donbt, whether, in case of inflammation of the stomach, bowels, or brain, leeches applied on the front of the abdomen, or on the temples, exert any effect at all considerable, as local means. Still there is no objection, and some small advantage, in applying them in these situations, since, while we are sure of the general effect, we have also some chance, at least, of obtaining a local one also. In the circumstances above detailed, not less than a dozen leeches need be applied. As a substitute for these, and as less troublesome and more prompt, cupping may be practised, to the extent of from six to sixteen ounces; the expediency of repeating it, and that to what extent, and how soon, will depend on the effect of the first depletion. After the leeching or cupping, a large and warm cataplasm should be applied. Of course all stimulant articles of food or drink will be suspended. Care must also be taken that no medicine should be given calculated to augment the irritation of the mucous membrane. If castor or olive oil are not rejected, nothing is more eligible, or more adapted to lessen, without irritation, the tension and fulness of the mucous membrane of the stomach, duodenum, and small intestines. Injections may be added, to encourage the action of the oil; and after the stomach and bowels are thus disembarrassed, they should be left, as regards purgatives, in entire repose, for from twelve to twent -four hours. Many refrigerant drinlss may be given - such as the one recommended by Sydenham in infiammations, composed of orange-flower water, nitrate of potass, and syrup; or the nitrate of potass may be dissolved in barley or rice water. The addition of the ipecacuan wine will be found useful in reducing the pulse, producing diaphoresis, (the establishment of which will greatly relieve the stomachic pain \&c.,) and also in promoting the restoration of the secre. tion of the gastric mucous membrane. If the pain or uneasiness at the epigastrium is great, and the thirst and heat considerable, iced water may be allowed, the feet and body being kept warm. The food, meantime, must consist of such articles as currant jelly, blancmange, calves'-foot jelly, or very light chicken soup, or decoctions of barley, rice, \&c.

Subsequently, if the tenderness at the epigastrium remains, after the moderation or disappearance of the other symptoms, and threatens to become chronic, occasional mustard epithems, a warm plaster, or perhaps, as more effectual, and even, in the end, less troublesome, the fiy blister may be resorted to.

In chronic gastritis, bloodletting is seldom or never required: a greater variety of internal measures may be adopted, and is expedient than in the acute form, in which gentle aperients, powerful refrigerants, and bloodletting, with abstinence or very meagre diet, are the chief means. In chronic gastritis, alteratives are admissible, of which the blue pill, with extract of rhubarb and ipecacuan, (the latter in as large proportion as possible, is decidedly the mnst eligible.

Draughts of the infusum lupuli, with a drachm or two of the liquor ammoniae acetatis, are useful, repeated frequently; and a few drops of ipecacuan wine may be advantageously added. If the subject of chronic gastritis is not of arthritic diatliesis, and not beyond middle life, an acidulous diet, such as apples, pears, grapes, currants, strawberries, and acidulous drink, such as cycler, perry, lemonade, claret, may be allowed; and if there are means and opportunity, the waters of Pyrmont, Carlsbad, Spa, Seltzer, Wiesbaden, or Stonefield, in Lincolnshire. Some French physicians allow, also, in this variety, chalybeate waters, in decoction of rice or barley-a permission which we think injudicious. If the patient is arthritic, and past middle life, his bowels must be regulated with blue pill, extract of rhubarb, and ipecacuan. He may take infusion of hop, with carbonate of soda, and colchicum wine. If opportunity offers, he may use the waters of Vichy or Plombières, and, in general, avoid acids. He must dress warmly, eat moderately, take regular exercise, and, if possible, seek travel, and change of air.

Bentinck-street, Manchester-square, Nov 1547.

ON THE

\section{USE OF CHLOROFORM IN THE PRACTICE OF MIDWIFERY.}

By I. B. BROWN, Consulting Accoucheur to the Paddington lying-in Charity.

Is the present stage of our investigations as to the use of this anæesthetic agent in obstetric practice, every new case must be considered valuable, and will give increased confidence in its administration. I had not seen Dr. Protheroe Smith's interesting paper when I treated the following case; but having read the pamphlet so clearly written by Professor
Simpson, I did not hesitate to try this powerful remedy in alleviating the pains of severe childbirth.

Mrs. W-, aged forty, the mother of seven children, sent for me at half-past five A.r. She had had labour-pains since one A.M. I found the os uteri dilated to the size of a crownpiece, but all the external parts dry and tense, the liquor amnii having been discharged many hours previously. The pains were severe, and not very efficient, being checked in their progress by the funis, which was found subsequently to be round the neck and left arm. I proceeded to administer the clloroform, by placing a small quantity on a pocket-handkerchief, and allowing her to breathe it. In half a minute it produced an agreealble state of stupor, and she suffered but little from the next pain. I paid great attention to the practical and judicious remarks which Dr. Simpson kindly gave me, in a private note accompanying his pamphlet,-viz., "In midwifery you do not require to keep the patient so sound and deep as in surgery, otherwise you will stop the pains; but she should be so deep as not to feel them. With chloro. form I give a few inhalations before each pain. In the interral, keep her just asleep, and no more." Thus I found every pain subdued as to the patient's suffering, but not at all as to its expulsive power. After the first two or three inhalations the external parts gave way, and became moist, soft, and yielding. The head, which did not present in the natural way, but with the ear under the arch of the pubes, and the occiput under the sacro-sciatic arch, in abont two hours descended to the perineum, and pressed hard upon it. I then gave a larger dose, and the child - a fine male - was born without the knowledge of the pationt, and she awoke in five minutes, hearing its cry. The placenta came away entire in ten minutes, whereas in all her previous labours she had always either hour-glass contraction, or retention from other causes. The uterus contracted well, and continued so; the patient had no bad symptom, either vomiting or headach. In all, I used only one drachm.

Oxford-square, Hyde-park, Nov, 1847.

\section{جRcbíctos.}

\section{On Indigestion: its Pathology and Treatment by the Local} A pplication of Uniform and Continuous Heat and Moisture. With an Account of an Improved Mode of applying Heat or Cold in Irritative and Inflammatory Diseases. By James Arrotr, M.D., Physician to the Brighton Dispensary. London: John Churchill. 8vo, 1847. pp. 107.

THe object and nature of this treatise may be well collected from the preface. In it the author first states the general belief of the power of heat and cold as remedial agents, and then points out that-

"There have existed, hitherto, no means of regulating the degree of heat and cold in their continuous application, and the consequence has been, that while ackmowledging their efficacy when they chance to be properly used, many practitioners have ceased employing them in an efficient manner, because of this uncertainty, and because of the injury which has so often been the result of their improper application. It is a principal purpose of this publication to show that the dose of temperature (if the expression may be used) can be regulated with precision."

Having, therefore, heat and cold as a remedial measure so well under his control, Dr. Arnott has employed it extensively, because he found that it supplied a great desideratum in therapeutics-viz., an expedient having sufficient power to reduce vascular excitement, without the hazardous effect of debilitating the general system, or causing local irritation.

"He has applied heat, combined with moisture, in irritative and in inflammatory affections of the great cavities; and cold combined generally with fluid pressure, in diseases of the skin and of the joints, in ulcers and in external inflammations. But the disease in which he has principally used the former application is indigestion. This being, moreover, the least under the remedial influence of other measures, the efficacy of heat and moisture in curing it has beell more unequivocal than in other diseases of the same class."

Five years have elapsed since Dr. Arnott first made known his method of applying temperature to the cure of disease; and yet, to his surprise, what he regarded as so obvious an improvement has made but little progress, even in hospitals, 